\title{
CARACTERÍsticas de CULTIVOS CELULARES PRIMARIOS DERIVADOS DE Sarconesiopsis magellanica (LE GUILLOU, 1842) (DIPTERA: CALLIPHORIDAE)
}

\section{PRIMARY CELL CULTURES DERIVED FROM Sarconesiopsis magellanica (LE GUILLOU, 1842) (DIPTERA: CALLIPHORIDAE)}

\author{
Mónica Cruz B. ${ }^{1}$, Felio J. Bello ${ }^{2}$
}

${ }^{1}$ Bióloga. Joven Investigador Colciencias. Laboratorio de Entomología Médica y Forense, Escuela de Medicina y Ciencias de la Salud, Universidad del Rosario; ${ }^{2}$ M.Sc. Ph.D. Laboratorio de Entomología Médica y Forense, Escuela de Medicina y Ciencias de la Salud, Universidad del Rosario. Bogotá D.C., Colombia. Dirección para correspondencia: Calle 63D No. 24-31, E-mail: felio.bello@urosario.edu.co

Rev. U.D.C.A Act. \& Div. Cient. 15(2): 313 - 321, 2012

\section{RESUMEN}

El objetivo principal del presente trabajo fue obtener cultivos celulares primarios derivados de tejido embrionario de Sarconesiopsis magellanica (Diptera: Calliphoridae), mosca importante por sus aplicaciones en el establecimiento del intervalo post-mortem. Se evaluaron siete medios de cultivo (Grace, Grace/L15, MM, VP12, MM/VP12, Eagle y Schneider), suplementados con $20 \%$ de suero fetal bovino. Se observó adhesión, crecimiento y proliferación celular en los medios L15, Schneider y Grace/L15, lográndose mejores resultados en los dos últimos. La obtención de la monocapa confluente, se presentó en un tiempo promedio de doce días, después de realizados los explantes. El patrón de crecimiento de los cultivos primarios mostró la presencia de vesículas con células adheridas a sus paredes, las cuales, ayudaron a la formación de la monocapa confluente. La morfología celular predominante en la monocapa correspondió a formas fibroblastoides y, en menor proporción, a epitelioides, mostrando las primeras una apariencia similar a células nerviosas. Adicionalmente, se registraron en los primeros días de los cultivos primarios, especialmente, en algunos conglomerados de células, movimientos contráctiles semejantes a los realizados por células musculares. Estos cultivos celulares primarios derivados de $S$. mangellanica representan, potencialmente, sustratos adecuados para realizar ensayos posteriores de susceptibilidad a infección con arbovirus y parásitos.

Palabras clave: Moscas, medios de cultivo, tejido embrionario, vesículas, morfología celular.

\section{SUMMARY}

The present work was aimed at obtaining and characterizing cell cultures from Sarconesiopsis magellanica embryonic tissue (Diptera: Calliphoridae). This fly is important by its applications in the establishment of post-mortem interval. This study evaluated seven culture medium (Grace, Grace/L15, MM, VP12, MMVP12, Eagle and Schneider), supplemented with $20 \%$ fetal bovine serum. The adhesion, cell growth and proliferation were observed in L15 medium, Schneider and Grace/L15, achieving better results in the last two. The confluent monolayer was present in an average of twelve days after that the explants were made. The growth pattern of the primary cultures showed the presence of vesicles with cells adhering to its walls, which helped to form a confluent monolayer. The predominant cell morphology in monolayer correspond to fibroblastoid a lesser extent to epithelioid, showing the first similar to nerve cells. Additionally, there was in the early days of primary cultures, especially in some clusters of cells, contractile movement, similar to those made by muscle cells. These primary cell cultures derived from $S$. magellanica represent potentially suitable substrates for further testing of susceptibility to infection with arboviruses and parasites.

Key words: Flies, culture media, embryonic tissue, vesicles, cell morphology.

\section{INTRODUCCIÓN}

Sarconesiopsis magellanica (Le Guillou, 1842) pertenece a la familia Calliphoridae y es una mosca necrófaga y 
hemisinantrópica (Mariluis \& Schnack, 1996; Pinilla et al. 2012). En Colombia, esta especie tiene, al igual que la mayoría de las pertenecientes a la familia Calliphoridae, importancia a nivel ecológico, médico y sanitario, debido a sus hábitos de alimentación y a las etapas en su desarrollo biológico, razón por la cual, pueden ser vectores mecánicos de patógenos, tales como virus, bacterias, hongos, protozoos y helmintos (Ferreira \& Barbola, 1998; Förster et al. 2007) y también sus larvas pueden llegar a causar miasis en algunos vertebrados, incluido el hombre (Stevens, 2003; Visciarelli et al. 2003; Pape et al. 2004; Montoya et al. 2009). Así mismo, S. magellanica es importante en investigaciones médicolegales, debido a que puede ser utilizada en la determinación del intervalo post-mortem, al participar como primer colonizador de cuerpos en descomposición (Martínez et al. 2007; Segura et al. 2009). En Bogotá, específicamente en una zona semirural, fue registrada como la primera especie colonizadora de cuerpos de cerdo en descomposición, el cual, a su vez, se considera el principal biomodelo animal usado para experimentación en Entomología Forense (Segura et al. 2009). La presencia de esta especie ha sido reportada en Argentina (Mariluis \& Mulieri, 2003), en Bolivia, en Chile, en Ecuador y en Perú (Pape et al. 2004). Mariluis \& Mulieri (2003) describen a este insecto como especialmente adaptado a las alturas, en razón a que se encuentra en zonas superiores a los $900 \mathrm{msnm}$. En Colombia, está distribuido en los departamentos de Antioquia, de Boyacá, de Cundinamarca y Norte de Santander (Pape et al. 2004).

Desde comienzos del sigloXX, algunos investigadores trataron de obtener células de insecto in vitro (Lynn, 2002), pero no fue sino hasta 1962 cuando Grace, a partir de ovarios de un lepidóptero, la polilla Emperador Australiana (Antheraea eucalypti Scott, 1864), estableció la primera línea celular. Desde entonces hasta nuestros días, se han establecido más de 500 líneas celulares de insectos, correspondientes a, aproximadamente, 120 especies, la mayoría, de las cuales, pertenecen a los órdenes Diptera y Lepidoptera (Lynn, 2001; 2007).

Los cultivos celulares de insectos han contribuido al desarrollo de estudios fisiológicos de las especies, de las cuales, se derivan (Khurad et al. 2009; Zhang et al. 2011). También, son herramientas importantes en campos como la inmunología, la biología del desarrollo y en investigaciones sobre biopesticidas (Suddep et al. 2005; Harrison \& Lynn 2008; Xu et al. 2010). Por otro lado, estos sustratos celulares son considerados un recurso potencial importante en biología molecular, debido a su uso en un amplio rango de investigaciones aplicadas (Wu \& Wang, 2006; Iwanaga et al. 2009); así mismo, han resultado de gran utilidad en el estudio de las interrelaciones parásito-hospedero (Takahashi et al. 1980; Côrtes et al. 2011), en la propagación de patógenos específicos (Hoshino et al. 2009), en biofarmacéutica y en la expresión de proteínas recombinantes (Iwanaga et al. 2009; Khurad et al 2009; Kharat et al. 2010; Pan et al. 2010; Zhang et al. 2011). Cervarix ${ }^{\circledR}$, vacuna contra el virus del papiloma humano, fue el primer producto comercial producido por el sistema baculovirus-vector (Mena \& Kamen, 2011). La aparición del sistema vector de expresión baculovirus a comienzos de 1980, para la producción de proteínas heterólogas, adicional a los avances en ingeniería metabólica, ha permitido convertir el cultivo de células de insecto en una nueva tecnología de gran utilidad en estudios biomédicos (Ikonomou et al. 2001), aumentando así el interés en el desarrollo de nuevas líneas celulares (Suddep et al. 2005).

Además de las aplicaciones de los cultivos celulares derivados de insectos, señaladas anteriormente, existe una demanda creciente de ellos en biología celular y, particularmente, en estudios genómicos funcionales de insectos, sin descartar el hecho que estas líneas celulares, originadas de una gran variedad de especies, difieran en su capacidad para replicar virus y expresar proteínas recombinantes (Hink et al. 1991; Iwanaga et al. 2009; Goodman et al. 2012), razón por la cual, se hace necesario establecer nuevas líneas celulares de insectos (Hoshino et al. 2009; Khurad et al. 2009; Wen et al. 2009; Pan et al. 2010; Zhang et al. 2011), precisamente, para apoyar y para avanzar en todos los procesos indicados. En la actualidad, no se conocen registros en la literatura especializada universal de cultivos celulares de $S$. magellanica. Para la familia Calliphoridae solamente existe un registro de cultivos celulares primarios, que corresponde a la especie Lucilia sericata (Echeverry et al. 2009). Por otro lado, con respecto a especies de importancia forense de la familia Sarcophagidae, se registra la línea celular de Sarcophaga peregrina (Takahashi et al. 1980).

El objetivo principal del presente trabajo fue obtener cultivos celulares primarios derivados de tejidos embrionarios de $S$. magellanica, los cuales, se caracterizaron de acuerdo con el patrón de crecimiento y la morfología celular.

\section{MATERIALES Y MÉTODOS}

Material biológico: Para la iniciación de los cultivos primarios de S. magellanica, se utilizaron huevos embrionados, tomados de una colonia previamente establecida, en el laboratorio de Entomología Médica y Forense de la Universidad del Rosario, mantenida a una temperatura entre $22 \mathrm{a} 25^{\circ} \mathrm{C}$; humedad relativa de $60-70 \%$ y periodos de luz y de oscuridad de doce horas. Como fuente de carbohidratos, se utilizó una torunda impregnada con una solución azucarada y suplementada con $1 \mathrm{~mL}$ de vitaminas del complejo B. 
Como alimento y sustrato proteico, para inducir las posturas de los adultos hembras, se utilizó hígado de cerdo.

Desinfección del material biológico y obtención de cultivos primarios: Los huevos recolectados de la colonia, aproximadamente 200 para cada ensayo, fueron previamente incubados en el insectario, durante 20 a 22 horas, seguido de una refrigeración a $4^{\circ} \mathrm{C}$ por tres horas y un tiempo adicional de incubación de dos horas, a $37^{\circ} \mathrm{C}$, antes de la realización del explante. Después del tiempo de incubación, se depositaron en un tubo estéril cónico Falcom de $15 \mathrm{~mL}$, donde se realizó un proceso de desinfección, de acuerdo con el procedimiento registrado por Figueroa et al. (2007), con algunas modificaciones. Se llevaron a cabo lavados seriados de los huevos, el primero de ellos con $8 \mathrm{~mL}$ de hipoclorito de sodio al $0,5 \%$ con agitación continua durante cinco minutos; luego, al decantarse, se retiró la solución y, a continuación, se realizó un segundo lavado con $8 \mathrm{~mL}$ de formaldehido al $5 \%$, también con agitación continua, durante cinco minutos. Finalmente, siguiendo los pasos anteriores, se efectuaron tres lavados sucesivos de los huevos, en agua destilada estéril con antibiótico (penicilina/estreptomicina al 1\%).

Después del procedimiento de asepsia, a los huevos se les adicionó $3 \mathrm{~mL}$ de tripsina al $1 \%$ y luego se llevaron a un homogenizador de tejidos, donde se maceraron. El producto del procedimiento anterior, se incubó durante cuatro minutos a $37^{\circ} \mathrm{C}$; pasado este tiempo, se adicionaron $5 \mathrm{~mL}$ del medio de crecimiento seleccionado, con el propósito de desactivar la tripsina. El contenido, se centrifugó a $432 \mathrm{~g}$, durante siete minutos. Después de descartar el sobrenadante, el precipitado fue resuspendido en $5 \mathrm{~mL}$ de medio de cultivo seleccionado y, de inmediato, se vertió la mezcla en un frasco de cultivo de $25 \mathrm{~cm}^{2}$. Finalmente, el frasco con el contenido, se llevó a incubación, a una temperatura de $28^{\circ} \mathrm{C}$, sin atmosfera de $\mathrm{CO}_{2}$.

Medios de cultivo evaluados: Para la iniciación de los cultivos celulares primarios, se evaluaron los medios de cultivo siguientes: L-15 (Gibco®), Grace/L-15 (Gibco®), Eagle MEM (Gibco®), MM (Mitsuhashi \& Maramorosh, 1964), VP12 (Varma \& Pudney, 1969), MM/VP12 (Varma \& Pudney 1969) y Schneider (Sigma $\left.{ }^{\circledR}\right)$; suplementados, cada uno de ellos, con $20 \%$ de Suero fetal Bovino (SFB) y una solución de antibiótico-antimicótico al $1 \%$.

Morfología celular y patrón de crecimiento: Se realizaron observaciones diarias de los cultivos primarios, haciendo uso de un microscopio invertido (Leica DMIL), donde se identificaron las formas celulares. También, se hizo seguimiento diario a las características del crecimiento y patrones morfológicos, que se fueron configurando en los cultivos, a través del tiempo.

\section{RESULTADOS Y DISCUSIÓN}

Iniciación de cultivos celulares primarios y medios de cultivo: El crecimiento celular, se inició a las 48 horas, posterior a la siembra de los tejidos embrionarios, en los medios L15, Grace/L15 y Schneider. No hubo crecimiento en los medios MM, VP12, MM/VP12 y Eagle (Tabla 1). La principal fuente para la obtención de cultivos primarios, se presentó alrededor de pequeños fragmentos del explante, adheridos a la superficie inferior del frasco de cultivo; sin embargo, hubo también proliferación de células sueltas, algunas, inicialmente, en suspensión y en otras, formando colonias aisladas, similar a lo registrado por Grasela et al. (2012), Li et al. (2012) y Zhang et al. (2012). El tiempo relativamente corto empleado en la iniciación del crecimiento celular, a partir de los tejidos embrionarios de $S$. magellanica sembrados en los tres medios de cultivos antes indicados como óptimos, es una característica poco común en cultivos celulares de insectos, lo cual, es excepcionalmente similar al tiempo post-siembra registrado en el medio de cultivo L-15, en la iniciación de los cultivos celulares primarios derivados de tejidos embrionarios de la mosca Lucilia sericata (Meigen, 1826) donde el crecimiento celular se inició en las primeras horas después de haberse realizado los explantes (Echeverry et al. 2009).

La selección del tiempo de incubación de los huevos constituye uno de los factores determinante para la iniciación del crecimiento celular y, en el presente trabajo, los mejores resultados, se lograron en aquellos que alcanzaron las dos terceras partes del desarrollo embrionario (22 y 24 horas de incubación), siendo similar esta situación a lo registrado en cultivos celulares de mosquitos (Charpentier et al. 1995; Bello et al. 2001; Ardila et al. 2005) y también de flebótomos (Rey et al. 2000; Zapata et al. 2005). Además, un período de incubación de los huevos a una temperatura de $37^{\circ} \mathrm{C}$, durante un tiempo no superior a dos horas, antes de su uso en los explantes de tejido embrionarios, tal como ocurrió en el presente trabajo, estimula la división celular e incrementa su metabolismo, lográndose, de esta forma, en los medios de cultivo óptimos, un menor tiempo en la iniciación del crecimiento y la proliferación celular de los cultivos primarios (Oelofsen et al. 1990).

Por otro lado, el tiempo empleado en la formación de las monocapas confluentes en los tres medios de cultivo (Figuras 1a, b, c) donde se inició el crecimiento celular, no se dio por igual en todos ellos; así tenemos que el medio de cultivo, con un registró menor de duración, fue Grace/L15, con ocho días, seguido de Schneider, con diez días y, por último, L15, con 19 días. Esta situación es diferente a lo registrado en los cultivos celulares primarios derivados de $L$. sericata, donde la formación de la monocapa celular se obtuvo solamente en el medio L15, a pesar que se evaluaron los mismos medios 
Tabla 1. Resumen del proceso de obtención de los cultivos celulares primarios derivados de tejidos embrionarios de $S$. magellanica.

\begin{tabular}{|c|c|c|c|c|c|}
\hline $\begin{array}{l}\text { Números de } \\
\text { explantes }\end{array}$ & Fuente & $\begin{array}{l}\text { Medio de } \\
\text { cultivo }\end{array}$ & $\begin{array}{c}\text { Inicio } \\
\text { crecimiento }\end{array}$ & Morfología celular & $\begin{array}{l}\text { Formación } \\
\text { monocapa }\end{array}$ \\
\hline 6 & Huevo & MM & ------- & ----------- & ----------- \\
\hline 6 & Huevo & VP12 & -------- & ------------ & ------------ \\
\hline 6 & Huevo & MM/VP12 & -------- & ----------- & ------------ \\
\hline 19 & Huevo & L15 & $1-3$ & Epitelioides y similares a nerviosas & SI \\
\hline 28 & Huevo & Grace/L15 & $1-3$ & Epitelioides y similares a nerviosas & $\mathrm{Si}$ \\
\hline 25 & Huevo & Schneider & $1-3$ & Epitelioides y similares a nerviosas & SI \\
\hline
\end{tabular}

de cultivo comparados con los empleados en el presente trabajo y, además, se estableció un tiempo mayor en la configuración de la monocapa, correspondiente a 45 días (Echeverry et al. 2009); sin embargo, en cultivos celulares de Aedes aegypti (Linnaeus, 1762), teniendo como fuente nutritiva el medio Grace/L15, se necesitaron seis meses para la formación de la monocapa confluente (Ardila et al. 2005).

Estas diferencias, en los tiempos prolongados o cortos, evidenciadas en la duración en la formación de las monocapa confluentes, dependen fundamentalmente del proceso de adaptación y de proliferación de las células en respuesta a las condiciones nutricionales, físico-químicas y ambientales, establecidas en los cultivos celulares primarios, derivados de insectos (Zhang et al. 2011). También, el hecho que algunos medios de cultivo, tal como se indicó arriba, no resultaron viables, se explica por la ausencia de nutrientes adecuados y suficientes para la adaptación y el crecimiento celular. Así mismo, los tres medios de cultivo donde hubo crecimiento celular y formación de monocapas tuvieron diferencias notables en el proceso de evolución y desarrollo de los subcultivos que se produjeron, así se pudo establecer que en L-15 solamente se obtuvieron tres pases, en Grace/L-15 hubo seis y en Schneider se han mantenido hasta el momento siete pases. Estas diferencias, se pueden deber a la variabilidad en la composición de los medios de cultivo, en términos de mayor o menor similitud con las sustancias que conforman la hemolinfa de los insectos, de donde se derivan los cultivos celulares (Grace, 1962).

En concordancia con la adaptación de las células, la evolución favorable de ellas en el crecimiento, en menor

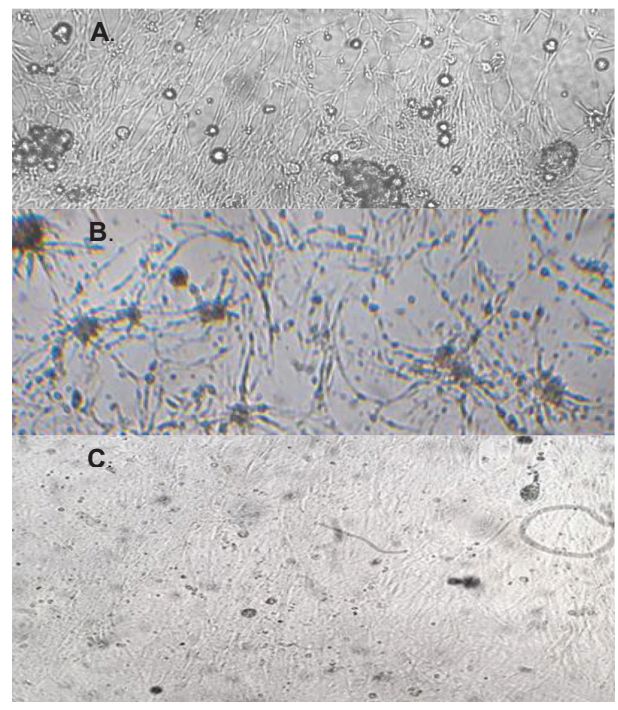

Figura 1. Monocapas confluentes obtenidas en diferentes medios de cultivo. A. Medio Grace/L15 después de 8 días de cultivo (20X). B. Medio Schneider después de 10 días de cultivo (20X). C. Medio L15 después de 19 días de cultivo (20X). 
tiempo, hasta la formación de la monocapa y el posterior desarrollo de subcultivos, a través de los pases sucesivos, los medios que mejores resultados produjeron fueron: Grace/ L15 y Schneider; sin embargo, el medio de cultivo en donde se presentó una mejor adaptación celular, a partir de los explantes de tejidos embrionarios de $S$. magellanica, fue Grace/L15, siendo, a su vez, el que tuvo concentraciones de iones de calcio, de potasio y de sodio, similares a las registradas en la hemolinfa de los dípteros de la familia Calliphoridae (Le Douarin, 1971), a la cual, pertenece dicha especie. Este hecho, probablemente, contribuyó en forma decisiva a simular las condiciones in vitro óptimas de las células cultivadas, parecidas a las del insecto seleccionado, permitiendo así la posterior evolución de los cultivos celulares primarios hasta la formación de la monocapa, en un tiempo relativamente menor. Por otro lado, el medio Schneider, a pesar de tener menores concentraciones de iones minerales, comparado con el anterior, es el único de los evaluados que registra la presencia de dos sustancias nutritivas necesarias en los procesos fisiológicos de los insectos: trehalosa y extracto de levadura. La primera sustancia es un componente importante en la hemolinfa de los insectos, que aumenta la sobrevivencia de las células en los cultivos, mientras que el extracto de levadura mejora la adherencia de los tejidos y de las células a la superficie de los frascos de cultivo, promoviendo, a su vez, la disociación de las células en las masas de tejido. En síntesis, estos dos compuestos y sus interacciones promueven la adherencia, el crecimiento y la propagación de células en la superficie de los frascos de cultivo (Zhang et al. 2011).
Patrón de crecimiento: Aunque en la iniciación de los cultivos primarios se registraron pocas células y fragmentos de tejidos en suspensión temporal en los medios de cultivo, el patrón definitivo en el crecimiento y en la propagación de las células se dio en forma de adherencia a la superficie; sin embargo, también se observaron vesículas (Figura 2) con células adheridas a su superficie, situación que fue común para los tres medios de cultivo señalados como óptimos, las cuales, después de un tiempo, relativamente corto, se disociaron y contribuyeron a la formación de nuevas colonias celulares en la superficie del frasco de cultivo que, luego de unirse con otras previamente constituidas, tuvieron una evolución favorable en su crecimiento ulterior hasta monocapas confluentes. Estas vesículas también han sido reportadas en trabajos previos sobre cultivos celulares de insectos, entre otros, por Bello et al. (1999); Suddep et al. (2005); Echeverry et al. (2009), Segura et al. (2012) y Goodman et al. (2012).

Otra característica fenotípica observada como un marcador importante en el crecimiento de los cultivos celulares primarios de $S$. magellanica, en los primeros días, fue la presencia de una contracción rítmica que se localizó en algunos conglomerados de células adheridas a la superficie de los frascos, pero, luego de los tres primeros subcultivos, no se volvió a observar. Este movimiento también se ha registrado en varios trabajos sobre establecimiento y caracterización de líneas celulares de insectos, tales como los efectuados por Inoue et al. (1991); Bello et al. (1999); Khurad et al. (2009); Echeverry et al. (2009); Wen et al. (2009); Pan et al. (2010) y Xu et al. (2010). Posiblemente, el movimiento rítmico es debido a la acción de proteínas

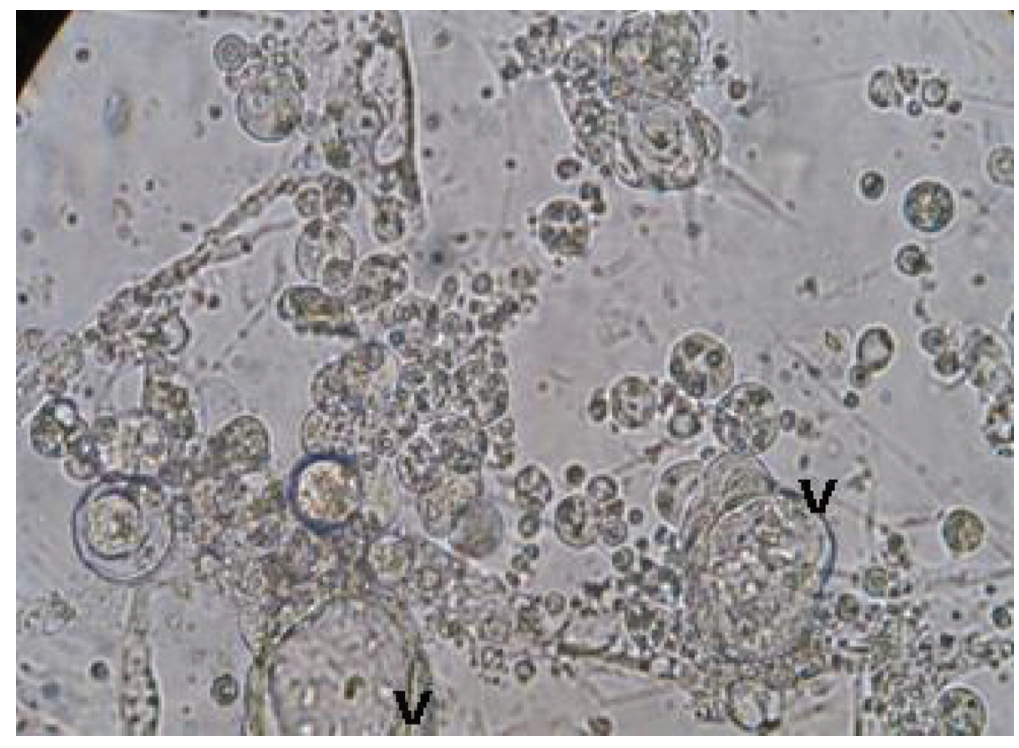

Figura 2. Vesículas observadas en los primeros días de cultivo en el medio Schneider (40X). 


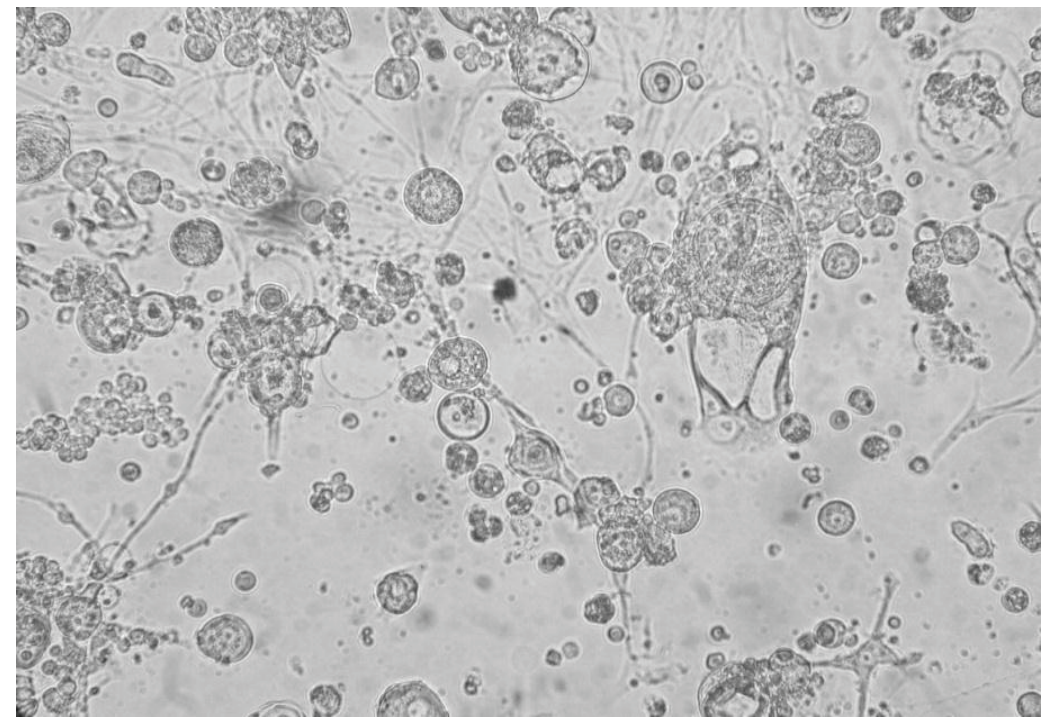

Figura 3. Morfología celular en los primeros días de cultivo en el medio Grace/L15 (20X).

contráctiles propias de células derivadas de tejido muscular (Segura et al. 2012). La pérdida del movimiento, a través del número de pases, puede ser consecuencia de un proceso de selección adaptativa de las células a las condiciones establecidas en el medio de cultivo (Takahashi et al. 1980; Khurad et al. 2009).

Morfología celular. La forma de las células al inicio de los cultivos celulares primarios fue heterogénea: esféricas pequeñas, alargadas discontinuas y gigantes irregulares (Figura 3). No obstante, a los pocos días del crecimiento celular, se configuraron mayoritariamente las formas alargadas fibroblastoides $y$, en menor proporción, las epitelioides, similar a lo registrado por Li et al. (2012) y Zhang et al. (2012), pero ya constituida la monocapa las formas fibroblastoides fueron prácticamente las únicas registradas. En los primeros subcultivos, se observaron en las células finos filamentos o prolongaciones citoplasmáticas que, algunas veces, formaron redes de apariencia similar a las células nerviosas. Esta situación es concordante con la descripción registrada por Echeverry et al. (2009) en los cultivos celulares primarios de L. sericata. La presencia de grupos con morfologías celular diferente en los cultivos celulares primarios, se debe, posiblemente, a los diversos tipos de tejidos disponibles en los huevos embrionados utilizados en los explantes (Rey et al. 2000; Miranda et al. 2008; Ardila et al. 2005).

En conclusión, se obtuvieron cultivos celulares primarios a partir de tejido embrionarios de $S$ magellanica, en los medios L-15, Grace/L15 y Schneider; sin embargo, los mejores resultados se lograron en los dos últimos medios.
Se estableció la tipificación del cultivo, mediante el patrón de crecimiento y las características morfológicas de las células hasta el desarrollo exitoso de monocapas confluentes, con lento crecimiento posterior, a través de los subcultivos. Estos sustratos celulares, se consideran una herramienta importante por sus aplicaciones potenciales en los campos biotecnológicos y biomédicos, incluyendo inmunología, endocrinología, toxicología, bioquímica y parasitología. De forma inicial, se usarán en ensayos de susceptibilidad a infecciones con arbovirus y también como sustratos para el desarrollo del ciclo biológico de algunos parásitos, principalmente, del género Leishmania (Côrtes et al. 2011).

Agradecimientos: A Colciencias, por la cofinanciación de la joven investigadora y a la Universidad del Rosario, Fondo de Investigaciones (FIUR), por la financiación del presente trabajo. Conflicto de intereses: El manuscrito fue preparado y revisado con la participación de todos los autores, quienes declaramos que no existe ningún conflicto de intereses que ponga en riesgo la validez de los resultados presentados.

\section{BIBLIOGRAFÍA}

1. ARDILA, A.; ESCOVAR, J.; BELLO, F. 2005. Características de nuevos cultivos celulares derivados de tejidos embrionarios de Aedes aegypti (Diptera: Culicidae). Biomédica (Colombia). 25(1):65-75.

2. BELLO, F.; RODRÍGUEZ, J.; MORALES, A.; OLANO, V. 1999. Estudio de cultivos celulares primarios 
de Psorophora confinnis (Diptera: Culicidae). Biomédica (Colombia). 19(2):127-135.

3. BELLO, F.; RODRÍGUEZ, J.; ESCOVAR, J.; OLANO, V.; MORALES, A.; GONZÁLEZ, M.; REY, G. 2001. A new continuous cell line from the mosquito Psorophora confinnis (Diptera: Culicidae) and its susceptibility to infections with some arboviruses. Mem. Inst. Oswaldo Cruz (Brasil). 96(6):865-873.

4. CHARPENTIER, G.; BELLONCIK, S.; DUCROS, G.; FONTENILLE, D.; TIAN, L.; QUIOT, J. 1995. Establishment and characterization of three cell lines from Aedes triseriatus (Diptera: Culicidae). J. Med. Entomol.(Estados Unidos). 32(6):793-800.

5. CÔRTES, L.; SILVA, R.; PEREIRA, B.; GUERRA, C.; ZAPATA, A.; BELLO, F.; FINKELSTEIN, L.; MADEIRA, M.; BRAZIL, R.; CÔRTE-REAL, S.; ALVES, C. 2011. Lulo cell line derived from Lutzomyia longipalpis (Diptera: Psychodidae): a novel model to assay Leishmania spp. and vector interaction. Parasit. Vectors (Inglaterra). 4:216220.

6. ECHEVERRY, L.; ZAPATA, A.; SEGURA, A.; BELLO, F. 2009. Estudio de cultivos celulares primarios derivados de Lucilia sericata (Diptera: Calliphoridae). Rev. Cienc. Salud (Colombia). 7(3):17-28.

7. FERREIRA, M.J.M.; BARBOLA, I.F. 1998. Sinantropía de Califorídeos (Insecta, Diptera) de Curitiba, Paraná, Brasil. Rev. Bras. Biol 58 (2): 203-209.

8. FIGUEROA, L.; FLORES, J.; RODRÍGUEZ, S. 2007. Método de cultivo de larvas de Lucilia sericata para terapia larval. Parasitol. Latinoam. (Chile). 62:79-82.

9. FÖRSTER, M.; KLIMPEL, S.; MEHLHORN, H.; SIEVERT, K.; MESSLER, S.; PFEFFER, K. 2007. Pilot study on synanthropic flies (e.g. Musca, Sarcophaga, Calliphora, Fannia, Lucilia, Stomoxys) as vectors of pathogenic microorganisms. Parasitol Res. 101:243-246.

10. GOODMAN, C.L.; STANLEY, D.; RINGBAUER, J.A. Jr.; BEEMAN, R.W.; SILVER, K.; PARK, Y. 2012. A cell line derived from the red flour beetle Tribolium castaneum (Coleoptera: Tenebrionidae). In Vitro Cell Dev Biol Anim. PMID: 22752637 [Epub ahead of print].
11. GRACE, T. 1962. Establishment of four strains of cells from insect tissues grown in vitro. Nature (Inglaterra). 195:788-789.

12. GRASELA, J.; MCINTOSH, A.; RINGBAUER, J.; JR, GOODMAN, C.; CARPENTER, J.; POPHAM, H. 2012. Development of cell lines from the cactophagous insect: Cactoblastis cactorum (Lepidoptera: Pyralidae) and their susceptibility to three baculoviruses. In Vitro Cell Dev. Biol. Anim. (Alemania). 48(5):293-300.

13. HARRISON, R.; LYNN, D. 2008. New cell lines derived from black cutworm, Agrotis ipsilon, that support replication of the A. ipsilon multiple nucleopolyhedrovirus and several group I nucleopolyhedroviruses. J. Invertebr Pathol (Estados Unidos). 99(1):28-34.

14. HINK, W.; THOMSEN, D.; DAVIDSON, D.; MEYER, A.; CASTELLINO, F. 1991. Expression of three recombinant proteins using baculovirus vectors in 23 insect cell lines. Biotech. Prog. (Estados Unidos). 7(1):9-14.

15. HOSHINO, K.; HIROSE, M.; IWABUCHI, K. 2009. A new insect cell line from the longicorn beetle Plagionotus christophi (Coleoptera: Cerambycidae). In Vitro Cell Dev. Biol. Anim. 45(1-2):19-22.

16. IKONOMOU, L.; BASTIN, G.; SCHNEIDER, Y.; AGATHOS, S. 2001. Design of an efficient medium for insect cell growth and recombinant protein production. In Vitro Cell Dev. Biol. Anim. 37(9):549-559.

17. INOUE, H.; KOBAYASHI, J.; KAWAKITA, H.; MIYAZAKI, J.; HIRABAYASHI, T. 1991. Insect muscle cell line forms contractile tissue networks In vitro. In Vitro Cell Dev. Biol. 27A(11):837-840.

18. IWANAGA, M.; ARAI, R.; SHIBANO, Y.; KAWASAKI, H.; IMANISHI, S. 2009. Establishment and characterization of the Bombyx mandarina cell line. J. Invertebr. Pathol. 101(2):124-129.

19. KHARAT, K.; SAWANT, M.; PETER, S.; HARDIKAR, B. 2010. Development and characterization of new cell line BPH22 from midgut epithelial cells of Poekilocerus pictus (Fabricius, 1775). In Vitro Cell Dev.Biol. Anim. 46(10):824-827.

20. KHURAD, A.; ZHANG, M.; DESHMUKH, C.; BAHEKAR, R.; TIPLE, A.; ZHANG, C. 2009. A new continuos 
cell line from larval ovaries of silkworm, Bombyx mori. In Vitro Cell Dev. Biol. Anim. 45(8):414-419.

21. LE DOUARIN, N. 1971. Organ culture methods. En: Vago, C. (ed.) Invertebrate tissue culture. Volume I. Nueva York: Academic Press. p.41-114.

22. LI, X.; QIN, Q.; ZHANG, N.; ZHU, W.; ZHANG, J.; WANG, H.; MIAO, L.; ZHANG, H. 2012. A new insect cell line from pupal ovary of Spodoptera exigua established by stimulation with $\mathrm{N}$-methylN'-nitro-N-nitrosoguanidine (MNNG). In Vitro Cell Dev. Biol. Anim. 48(5):271-275.

23. LYNN, D. 2002. Methods for maintaining insect cell cultures. J. Insect. Sci. (Estados Unidos). 2(9):1-6.

24. LYNN, D. 2001. Novel techniques to establish new insect cell lines. In vitro Cell Dev. Biol. 37(6):319-321.

25. LYNN, D. 2007. Available lepidopteran insect cell lines. In: Murhamme D. (ed.) Methods in molecular biology: baculoviruses and insect cell expression protocols, vol. $3382^{\text {nd }}$ ed. Humana, Totowa, New Jersey. p.117-137.

26. MARILUIS, J.; MULIERI, P. 2003. The distribution of the Calliphoridae in Argentina (Diptera). Rev. Soc. Entomol. Argent. 62(1):85-97.

27. MARILUIS, J.; SCHNACK, J. 1996. Elenco específico y aspectos ecológicos de Calliphoridae (Insecta, Diptera) de San Carlos de Bariloche, Argentina. Bol. R. Soc. Esp. Hist. Nat. Secc. Biol. 92(14):203-213.

28. MARTÍNEZ, E.; DUQUE, P.; WOLFF, M. 2007. Succession pattern of carrion-feeding insects in Paramo, Colombia. Forensic Sci. Int. (Irlanda).166(2-3):182-189.

29. MENA, J.A.; KAMEN, A.A. 2011. Insect cell technology is a versatile and robust vaccine manufacturing platform. Expert Rev Vaccines. 10(7):1063-1081.

30. MIRANDA, A.; SARMIENTO, L.; CALDAS, M.; ZAPATA, C.; BELLO, F. 2008. Morfología y citoquímica de cultivos celulares de Aedes aegypti (Diptera: Culicidae) y susceptibilidad a Leishmania panamensis (Kinetoplastida: Trypanosomatidae). Rev. Biol. Trop. (Costa Rica). 56(2):447-458.

31. MITSUHASHI, J.; MARAMOROSH, K. 1964. Leafhopper tissue culture: embryonic, nymphal and imaginal tissues from aseptic insects. Contrib Boyce Thompson Inst (Estados Unidos). 22:435-460.

32. OELOFSEN, M.; GERICKE, A.; SMITH, M.; VAN DER LINDE, T. 1990. Establishment and characterization of a cell line from the mosquito Culex (Culex) theileri (Diptera: Culidae) and its susceptibility to infection with arbovirus. J. Med. Ent. (Estados Unidos). 27(6):939-944.

33. MONTOYA, A.; SANCHEZ, J.; WOLFF, M. 2009. Sinantropía de Calliphoridae (Diptera) del Municipio La Pintada, Antioquia - Colombia. Rev. Colomb. Entomol. 35(1):73-82.

34. PAN, M.; CAI, X.; LIU, M.; LV, J.; TANG, H.; TAN, J.; LU, C. 2010. Establishment and characterization of an ovarian cell line of the silkworm. Bombyx mori. Tissue cell. (Estados Unidos). 42(1):42-46.

35. PAPE, T.; WOLFF, M.; AMAT, E. 2004. Los Califóridos, Éstridos, Rinofóridos y Sarcofágidos (Diptera: Calliphoridae, Oestridae, Rhinophoridae, Sarcophagidae) de Colombia. Biota Colomb. 5(2): 201-208.

36. PINILLA, Y.; SEGURA, A.; BELLO, F. 2012. Synanthropy of Calliphoridae and Sarcophagidae (Diptera) in Bogotá, Colombia. Neotrop Entomol (Brasil). 41(3):237-242.

37. REY, G.; FERRO, C.; BELLO, F. 2000. Establishment and characterization of a new continuous cell line from Lutzomyia longipalpis (Diptera: Psychodidae) and its susceptibility to infections with arboviruses and Leishmania chagasi. Mem. Inst. Oswaldo Cruz (Brasil). 95(1):103-110.

38. SEGURA, N.; USAQUÉN, W.; SÁNCHEZ, M.; CHUAIRE, L.; BELLO, F. 2009. Succession pattern of cadaverous entomofauna in a semi-rural area of Bogotá, Colombia. Forensic Sci. Int. (Irlanda). 187(1-3):66-72.

39. SEGURA, N.; SANTAMARÍA, E.; CABRERA, O.; BELLO, F. 2012. Establishment and characterisation of a new cell line derived from Culex quinquefasciatus (Diptera: Culicidae). Mem. Inst. Oswaldo Cruz. 107(1):89-95.

40. STEVENS, J.R. 2003. The evolution of myiasis in blowflies (Calliphoridae). Int. J. Parasitol. 33:11051113. 
41. SUDDEP, A.; KHUSHIRAMANI, R.; ATHAWALE, S.; MISHRA, A.; MOURYA, D. 2005. Characterization of a newly established potato tuber moth (Phthorimaea operculella Zeller) cell line. Indian J. Med. Res. 121(3):159-163.

42. TAKAHASHI, M.; MITSUHASHI, J.; OHTAKI, T. 1980. Establishment of a cell line from embryonic tissues of the fleshfly, Sarcophaga peregrine (insect: Diptera). Developm., Growth Differ. (Japón). 22(1):11-19.

43. VARMA, M.; PUDNEY, M. 1969. The growth and serial passage of cell lines from Aedes aegypti $(\mathrm{L})$ larvae in different media. J. Med. Entomol. (Estados Unidos). 6(4):432-439.

44. VISCIARELLI, E.C.; GARCÍA, S.H.; SALOMÓN, C.; JOFRÉ, C.; COSTAMAGNA, S.R. 2003. Un caso de miasis humana por Cochliomyia hominivorax (Diptera: Calliphoridae) asociado a pediculosis en Mendoza, Argentina. Parasitol. Latinoam. 58:166168.

45. WEN, F.; ZHANG, Y.; QU, L.; ZHANG, H.; YANG, Z.; QIN, Q.; WANG, Y.; WANG, W. 2009. Two new cell lines originated from the embryos of Clostera anachoreta (Lepidoptera: Notodontidae): characterization and susceptibility to baculoviruses. In Vitro Cell. Dev. Biol. Anim. 45(8):409-413.

46. WU, C.; WANG, C. 2006. New cell lines from Lymantria Xylina (Lepidoptera: Lymantriidae):
Characterization and susceptibility to baculoviruses. J. Invertebr. Pathol. 93(3):186-191.

47. XU, F.; LYNN, D.; ROODE, E.; MUÑOZ, D.; VAN LENT, J.; VLAK, J.; VAN OERS, M. 2010. Establishment of a cell line from Chrysodeixis chalcites permissive for Chrysodeixis chalcites and Trichoplusia ni nucleopolyhedrovirus. J. Invertebr. Pathol. 105(1):56-62.

48. ZAPATA, A.; CÁRDENAS, E.; BELLO, F. 2005. Characterization of cell cultures derived from Lutzomyia spinicrassa (Diptera: Psychodidae) and their susceptibility to infection with Leishmania (Viannia) braziliensis. Med. Sci. Monit. (Estados Unidos).11(12):457-464.

49. ZHANG, X.; FENG, Y.; DING, W.; CHEN, X.; WANG, C.; MA, T. 2011. Establishment and characterization of an embryonic cell line from Gampsocleis gratiosa (Orthoptera: Tettigoniidae). In Vitro Cell. Dev. Biol. Anim. 47(4):327-332.

50. ZHANG, X.; FENG, Y.; DING, W.; CHEN, X.; WANG, C.; MA, T. 2012. Characterization of a new insect cell line that is derived from the neonate larvae of Papilio xuthus (Lepidoptera: Papilionidae) and its susceptibility to AcNPV. Tissue Cell. (Inglaterra). 44(3):137-142.

Recibido: Febrero 15 de 2012

Aceptado: Agosto 21 de 2012 